\title{
ENVIRONMENTAL ASSESSMENT OF APPLYING INNOVATIONS IN THE ENERGY SECTOR OF THE REGION (BASED ON IRKUTSK REGION) ${ }^{1}$
}

\author{
Boris G. Saneev \\ Melentiev Energy Systems Institute of the Siberian Branch of the Russian Academy of Sciences, \\ Irkutsk, Russian Federation \\ Elena P. Majsjuk \\ Melentiev Energy Systems Institute of the Siberian Branch of the Russian Academy of Sciences, \\ Irkutsk, Russian Federation \\ Svetlana Ju. Muzychuk \\ Melentiev Energy Systems Institute of the Siberian Branch of the Russian Academy of Sciences, \\ Irkutsk, Russian Federation
}

\begin{abstract}
The growth of energy efficiency in Russian economy is a priority for its development. The main role in this process will be played by the transition to innovative energy. The use of innovative technologies is an important factor in the development of economy and energy. In these conditions, it is necessary to develop new approaches to the substantiation of development forecasts. Irkutsk region has large reserves of energy resources. The innovative development of energy in Irkutsk region will increase the energy efficiency of economy and improve the state of the environment. The introduction of modern technological measures will reduce fuel consumption. The solution to this problem is important for Irkutsk region as an environmentally disadvantaged region. This fact determines the relevance of the study. The aim of the study is determining the degree of influence of innovative development of energy on the ecology of the region. The article shows the main directions of innovative development of the energy sector of Irkutsk region and gives their environmental assessment. Research methods are the system analysis, balance methods, statistical methods. The authors develop a method for assessing the impact of the innovative energy development on the ecological state of the region, and create model-computer tools. The results can be used by regional authorities and energy companies to forecast and manage the innovative development of energy in Irkutsk region.

Key words: fuel and energy complex, Irkutsk region, innovations, natural environment, best available technologies, emissions of harmful substances.

Citation. Saneev B.G., Majsjuk E.P., Muzychuk S.J. Environmental Assessment of Applying Innovations in the Energy Sector of the Region (Based on Irkutsk Region). Journal of Volgograd State University. Economics, 2020, vol. 22, no. 1, pp. 95-107. (in Russian). DOI: https://doi.org/10.15688/ek.jvolsu.2020.1.9

\section{ЭКОЛОГИЧЕСКАЯ ОЦЕНКА ПРИМЕНЕНИЯ ИННОВАЦИЙ В ЭНЕРГЕТИКЕ РЕГИОНА (НА ПРИМЕРЕ ИРКУТСКОЙ ОБЛАСТИ) ${ }^{1}$}

\section{Борис Григорьевич Санеев}

Институт систем энергетики им. Л.А. Мелентьева Сибирского отделения РАН, г. Иркутск, Российская Федерация 


\title{
Елена Петровна Майсюк
}

Институт систем энергетики им. Л.А. Мелентьева Сибирского отделения РАН, г. Иркутск, Российская Федерация

\section{Светлана Юрьевна Музычук}

Институт систем энергетики им. Л.А. Мелентьева Сибирского отделения РАН, г. Иркутск, Российская Федерация

\begin{abstract}
Аннотация. Важнейшим направлением развития современной экономики России является рост ее энергоэффективности, связанный с переходом к инновационной энергетике. Использование инновационных технологий - важный фактор, влияющий на развитие экономики и энергетики, что вызывает необходимость разрабатывать новые подходы к обоснованию прогнозов их развития. Иркугская область располагает значительными запасами топливно-энергетических ресурсов. Инновационное развитие энергетики позволит повысить энергоэффективность экономики и улучшить состояние природной среды за счет сокращения потребления топлива и внедрения современных технологических мероприятий. Решение данной проблемы представляется важным для Иркугской области в связи с тем, что она является одним из экологически неблагополучных регионов России. Цель исследования заключается в определении степени влияния инновационного развития энергетики на экологию региона. В статье показаны основные направления инновационного развития энергетики Иркутской области и дана их экологическая оценка. Методы исследования - системный анализ, балансовые, статистические методы. Авторами разработан метод оценки влияния инновационного развития топливноэнергетического комплекса на экологическое состояние региона, создан модельно-компьютерный инструментарий. Результаты могут использоваться региональными органами власти и энергетическими компаниями для прогнозирования и управления в рамках инновационного развития энергетики Иркутской области.

Ключевые слова: топливно-энергетический комплекс, Иркутская область, инновации, природная среда, наилучшие доступные технологии, выбросы вредных веществ.
\end{abstract}

Цитирование. Санеев Б. Г., Майсюк Е. П., Музычук С. Ю. Экологическая оценка применения инноваций в энергетике региона (на примере Иркутской области) // Вестник Волгоградского государственного университета. Экономика. - 2020. - Т. 22, № 1. - C. 95-107. - DOI: https://doi.org/10.15688/ek.jvolsu.2020.1.9

\section{Введение}

Изменения в экономике страны, связанные с переходом к интеллектуальной энергетике, вызывают необходимость разрабатывать новые подходы к обоснованию прогнозов инновационного развития отраслей топливно-энергетического комплекса (далее - ТЭК) России и ее регионов. Применение инновационных энергетических технологий приводит к изменениям в структуре поставок и потребления топливно-энергетических ресурсов (далее - ТЭР), что необходимо учитывать при анализе и долгосрочном прогнозировании инновационного развития ТЭК. Внедрение инновационных технологий оказывает большое влияние на решение таких задач, как повышение энергоэффективности, рост энергетической безопасности, рост конкурентоспособности страны и ее регионов, снижение экологических проблем. Поэтому учет возможного использования инновационных технологий становится важным факто- ром, влияющим на долгосрочные прогнозы развития экономики и ТЭК.

Иркутская область располагает значительным потенциалом в сфере применения инноваций в ТЭК, чему способствует богатая топливно-сырьевая база (для развития топливодобывающих отраслей на новой технологической основе), большое количество энергогенерирующих предприятий (для обновления и модернизации производственного оборудования), реализация крупных инвестиционных проектов (для использования передовых технологических решений при создании новых энергогенерирующих предприятий), наличие большого числа изолированных от централизованного энергоснабжения потребителей (для сооружения новых источников на возобновляемых энергоресурсах).

Эффективность использования ТЭР является одной из важных задач в реализации национальных интересов как региона, так и страны в целом. Реализация инновационного развития отраслей ТЭК, способствующего 
энергосбережению, позволит существенно повысить энергоэффективность экономики, что напрямую связано с состоянием природной среды, поскольку сокращение потребления топлива, особенно угля, снизит выбросы вредных веществ в окружающую среду, что очень важно для Иркутской области, так как она относится к одному из экологически неблагополучных регионов России.

Поскольку предприятия электро- и теплоэнергетики вносят основной вклад в загрязнение окружающей среды (их доля в выбросах вредных веществ от стационарных источников составляет около $80 \%$ ), то развитие ТЭК Иркутской области по инновационному сценарию окажет значительное влияние на экологию региона. Определение степени этого влияния является целью исследования.

Для проведения исследований по материалам зарубежных и российских источников разработана информационно-аналитическая база инновационных технологий в энергетике и создан модельно-компьютерный инструментарий оценки влияния инновационного развития ТЭК Иркутской области на состояние природной среды.

\section{Краткий обзор \\ зарубежных и российских источников по применению инновационных технологий в энергетике}

Одной из наиболее авторитетных организаций в сфере разработки инноваций для ТЭК является Международное энергетическое агентство (далее - МЭА), содействующее обеспечению бесперебойного и доступного энергоснабжения потребителей в странах членах $\mathrm{OЭCP}^{2}$ с сохранением окружающей среды. В МЭА существует проект «Перспективы энергетических технологий», который знакомит заинтересованных лиц с существующими в мире перспективными энергетическими технологиями. В докладе МЭА «Перспективы энергетических технологий 2017» представлены результаты исследования влияния научно-технического прогресса на динамику развития ТЭК, от которой будет зависеть энергетическая и экологическая безопасность, а также экономическая стабильность стран ОЭСР в течение последующих десятилетий [Energy Technology ...]. По данным МЭА внедрение инновационных технологий в электроэнергетике в мировом масштабе обеспечит ежегодную экономию топлива в объеме около 950-1100 млн т у.т. (что соответствует общему потреблению природного топлива в России за 2018 г. ${ }^{3}$ [Баланс энергоресурсов ...].

«Японский бизнес-альянс по продвижению интеллектуальных энергетических систем во всем мире (JASE-World)» - организация, созданная в 2008 г. для распространения передовых японских энергосберегающих разработок. В сборнике «Японские продукты и технологии интеллектуальной энергетики» [Japanese Smart ... , 2017] приведено большое количество инноваций, которые используются в различных сферах деятельности (включая ТЭК) в Японии [Японские ..., 2017].

Передовые технологии, для которых характерна высокая энергоэффективность и использование возобновляемых источников энергии (далее - ВИЭ), вносят большой вклад в энергосбережение Японии, позволяя при росте ВВП страны в 2,4 раза с середины 1970-х гг. до настоящего времени увеличить энергопотребление всего в 1,3 раза [Японские ..., 2017].

Изучение опыта применения инновационных технологий в развитых странах мира очень важно для России, разрабатывающей свои инновации в различных сферах деятельности. Стратегической задачей, стоящей перед ТЭК России, является инновационное развитие его отраслей, для чего необходимо внедрение технологических инноваций.

В настоящее время инновационное развитие в ТЭК России реализуется согласно разработанным Министерством энергетики РФ директивным документам, к которым относятся: «Прогноз научно-технологического развития отраслей ТЭК России на период до 2035 года» (далее - «Прогноз НТР») [Прогноз ..., 2016]; «дорожная карта» «Внедрение инновационных технологий и современных материалов в отраслях ТЭК» [Внедрение ..., 2014]; «дорожная карта» «Энерджинет» Национальной технологической инициативы (далее - НТИ) [Энерджинет ... , 2016]; национальный проект «Интеллектуальная энергетическая система России» [Национальный проект ..., 2016]. 
В «Прогнозе НТР» перечислены передовые технологические новшества, способные оказать наибольший эффект на развитие российской энергетики. К наиболее перспективным направлениям развития в электроэнергетике относятся: «цифровизация энергетики» (внедрение систем автоматизированной защиты и управления электрическими подстанциями); развитие технологий активно-адаптивных электрических сетей, технологических концепций «SmartGrid» и «Энерджинет»; внедрение нового электротехнического, электромеханического и электронного оборудования. В «Прогнозе НТР» для ТЭК России перечислены 24 основные критические (передовые) отраслевые технологии, внедрение и распространение которых способно обеспечить крупномасштабный экономический эффект, что необходимо для предотвращения угроз энергетической безопасности и обеспечения технологической независимости страны [Прогноз ..., 2016]. В электроэнергетике к инновационным относятся следующие технологии: газотурбинные установки большой мощности с высоким КПД; технологии экологически чистого использования твердого топлива (энергоблоки на суперсверхкритические параметры пара, энергоблоки со сжиганием угля в циркулирующем кипящем слое, технологии газификации углей с последующим использованием синтез-газа в парогазовом цикле и др.); технологии когенерации для распределенной энергетики; технологии интеллектуальных систем автоматического управления электрической сетью; электрохимические топливные элементы и аккумуляторы большой емкости и мощности; технологии производства взрывозащищенных электродвигателей высокого напряжения; производства высоковольтных коммутационных аппаратов на базе высокотемпературной сверхпроводимости; технологии цифровой подстанции [Прогноз ..., 2016].

К числу перспективных направлений, влияющих на рост технологического развития ТЭК России и ее регионов, в «Прогнозе НТР» также отнесены водородная энергетика, малая распределенная генерация с использованием ВИЭ, фотоэлектрические преобразователи, сетевые накопители [Прогноз ..., 2016].

В рамках НТИ разработана «дорожная карта» «Энерджинет», согласно которой пла- нируется реализация ряда «пилотных» проектов в сферах повышения надежности и гибкости сетей электропередачи, развития интеллектуальной распределенной энергетики и потребительских сервисов, необходимых при реализации решений для «активного потребителя» [Энерджинет ... , 2016].

\section{Результаты и обсуждение}

\section{Стратегический сиенарий развития энергетики Иркутской области}

Информационно-аналитическая база инновационных технологий в энергетике, предназначенная для комплексного анализа и долгосрочного прогнозирования инновационного развития ТЭК Иркутской области, сформирована в соответствии с директивными документами Минэнерго РФ, и по большей части ее составили перечисленные в «Прогнозе НТР» инновационные технологии, также учтен ряд наиболее перспективных технологических решений и разработок, реализуемых в России и экономически развитых станах мира. В результате использования созданного авторами модельно-компьютерного инструментария разработан прогноз стратегического (инновационного) сценария развития ТЭК Иркутской области. Динамика производственных показателей стратегического сценария приведена в таблице 1.

Стратегический (инновационный) сценарий развития энергетики Иркутской области характеризуется оптимальным вовлечением в топливный баланс природного газа и постепенным переходом на наилучшие доступные технологии (далее - НДТ), что окажет положительное влияние на экологию региона.

Экологическая оценка инновационного развития энергетики

В настоящее время с учетом требований Правительства РФ и Министрества природных ресурсов и экологии России разработаны различные нормативные акты для внедрения инновационных технологий для перехода на НДТ [Распоряжение Правительства от 19.03.2014 № 398-р ...; Внедрение ... , 2014]. 
Б.Г. Санеев, Е.П. Майсюк, С.Ю. Музычук. Экологическая оценка применения инноваций в энергетике региона

В целом к НДТ относятся только те технологии, которые обеспечивают высокое качество выпускаемой продукции, экономически оправданны и получили свое широкое распространение в России и за рубежом. Для крупных энергоисточников к таким технологиям следует относить те, использование которых оказывает наименьшее воздействие на элементы природной среды с учетом экономической эффективности, а также сроков их внедрения [Методические рекомендации по определению ...; Очистка выбросов ..., 2016]. Для обеспечения и реализации мер по переходу предприятий теплоэнергетики на НДТ разработан информационно-технический справочник по наилучшим доступным тех- нологиям (ИТС 38-2017) «Сжигание топлива на крупных установках в целях производства энергии» [Сжигание топлива ...].

Для снижения эмиссии твердых частиц на тепловых электростанциях (далее - ТЭС) к НДТ отнесены технологии очистки уходящих газов с эффективностью до $99 \%$ и выше (табл. 2) [Распоряжение Правительства от 19.03.2014 № 398-p ....].

Атмосфероохранные технологии ТЭС по снижению газообразных выбросов (оксидов азота и серы) связаны как с реорганизацией процесса сжигания углей, так и установкой улавливающих устройств. Имеются различные методы, позволяющие снизить образование оксидов азота в 2-3 раза и более (табл. 3).

\section{Стратегический сценарий развития ТЭК Иркутской области}

\begin{tabular}{|l|c|c|c|c|}
\hline \multicolumn{1}{|c|}{ Показатель } & 2017 г. & $2019-2025$ гг. & $2026-2030$ гг. & $2031-2035$ гг. \\
\hline $\begin{array}{l}\text { Добыча ТЭР: } \\
\text { - уголь, млн т }\end{array}$ & 12,2 & $14-15$ & $15-18$ & $17-20$ \\
\hline - нефть (с газовым конденсатом), млн т & 18,5 & $18-20$ & $19-23$ & $20-25$ \\
\hline $\begin{array}{l}\text { - природный газ (включая попутный), } \\
\text { млрд м }\end{array}$ & 2,6 & $6-10$ & $11-20$ & $25-35$ \\
\hline $\begin{array}{l}\text { Производство ТЭР: } \\
\text { - электроэнергия, млрд м }\end{array}$ & 48,8 & $50-55$ & $60-65$ & $70-75$ \\
\hline - тепловая энергия, млн Гкал & 37,5 & $40-45$ & $48-52$ & $53-57$ \\
\hline - нефтепродукты, млн т & 9,7 & $10-11$ & $11-12$ & $11-12$ \\
\hline
\end{tabular}

Примечание. Составлено авторами.

Таблииа 2

Характеристика основных НДТ по снижению выбросов твердых частиц

\begin{tabular}{|l|c|c|c|c|c|}
\hline \multirow{2}{*}{\multicolumn{1}{c|}{ Технология }} & \multirow{2}{*}{$\begin{array}{c}\text { Степень } \\
\text { очистки, \% }\end{array}$} & \multicolumn{2}{|c|}{ Удельные кап. затраты, } & \multicolumn{2}{c|}{ Время внедрения, мес.* } \\
\cline { 3 - 6 } & & $\min$ & $\max$ & $\min$ & $\max$ \\
\hline Электрофильтры & $99,5-99,9$ & 1080 & 2900 & 12 & 18 \\
\hline Эмульгаторы & 99,5 & 320 & 540 & 10 & 16 \\
\hline Скрубберы с трубами Вентури & 98,5 & 290 & 470 & 10 & 16 \\
\hline Рукавные фильтры & 99,9 & 1700 & 2800 & 12 & 18 \\
\hline
\end{tabular}
процедур.

Примечание. Составлено авторами. * - указано время работ на котле без учета проектных и экспертных

Таблица 3

Характеристика некоторых НДТ по снижению выбросов оксидов азота

\begin{tabular}{|c|c|c|c|c|c|}
\hline \multirow[t]{2}{*}{ Технология } & \multirow{2}{*}{$\begin{array}{l}\text { Потенциальное } \\
\text { сокращение, \% }\end{array}$} & \multicolumn{2}{|c|}{$\begin{array}{c}\text { Удельные кап. затраты, } \\
\text { руб./кВт }\end{array}$} & \multicolumn{2}{|c|}{$\begin{array}{c}\text { Время для внедрения, } \\
\text { мес.* }\end{array}$} \\
\hline & & $\min$ & $\max$ & $\min$ & $\max$ \\
\hline Рециркуляция дымовых газов & До 20 & 20 & 70 & 0,5 & 3,0 \\
\hline Двухступенчатое сжигание & До 45 & 70 & 140 & 2,0 & 3,0 \\
\hline Малотоксичные горелки & $30-40$ & 60 & 200 & 2,0 & 4,0 \\
\hline $\begin{array}{l}\text { Малотоксичные горелки и сту- } \\
\text { пенчатый ввод воздуха }\end{array}$ & $44-73$ & 135 & 250 & 1,5 & 2,5 \\
\hline $\begin{array}{l}\text { Малотоксичные горелки с двух- } \\
\text { ступенчатым сжиганием и ре- } \\
\text { циркуляцией дымовых газов }\end{array}$ & $50-78$ & 150 & 400 & 2,0 & 6,0 \\
\hline
\end{tabular}

Примечание. Составлено авторами по: [Распоряжение Правительства от 19.03.2014 № 398-р ...]. *_ указано время работ на котле без учета проектных и экспертных процедур. 
Методы подавления образования оксидов азота в процессе сжигания признаны наиболее эффективными НДТ и нашли свое применение на всех угольных станциях. Методы очистки уходящих газов от оксидов азота достаточно эффективны, однако являются дорогостоящими и широкого распространения не получили.

Основной экологической проблемой крупных энергообъектов является снижение эмиссии оксидов серы, которую возможно решить в процессе сжигания углей, когда часть $\mathrm{SO}_{2}$ связывается золой в топке. Доля серы, которая может быть связана в топке, зависит от зольности топлива и содержания свободной щелочи в летучей золе, а также от способа шлакоудаления. Так, эффективность связывания оксидов серы при сжигании канско-ачинских углей может достигать $20 \%$.

Технологии по улавливанию оксидов серы на действующих ТЭС России до настоящего времени промышленно не внедряются, поэтому в качестве основной меры снижения выбросов предлагается использовать уголь с низким содержанием серы.

Для котельных наиболее эффективными и доступными технологиями являются меры по подготовке топлива к сжиганию, что позволит снизить выбросы твердых частиц до 20-30 \%, к ним относятся: повышение качества топлива; обеспечение надлежащих условий хранения угля (контроль влажности); сортировка угля перед его использованием; обеспечение режимов сжигания топлива; использование конструктивных мер для улучшения его выгорания, снижения тепловых потерь за счет уменьшения присосов воздуха; организация дополнительной футеровки котлов и пр.

Необходима модернизация золоулавливающих устройств крупных угольных котельных с доведением степени очистки от твердых частиц до не менее 80-85\%. Для снижения выбросов оксидов азота на 20-30 \% в котельных необходимо внедрение систем рециркуляции газов, ступенчатого сжигания топлива и использование присадок в виде известняка.

С учетом обозначенных экологических возможностей природоохранных технологий для энергетических объектов Иркутской области предлагается:
- для ТЭС: широкое внедрение малотоксичных горелок с двухступенчатым сжиганием и рециркуляцией дымовых газов, позволяющих снизать выброс оксидов азота до $50 \%$; увеличение степени очистки уходящих газов от твердых частиц до 97-97,5 \% за счет модернизации существующих систем золоулавливания и/или установки новых современных систем очистки уходящих газов (эмульгаторов, рукавных фильтров); осуществление своевременных ремонтов технологического и очистного оборудования; продолжение применения существующих мер по регулированию режимов работы станций;

- для котельных: повсеместное использование мер предварительной подготовки топлива к сжиганию как в крупных, так и в мелких котельных.

В зависимости от перспективных объемов потребления различных видов топлива, их качественного состава, условий сжигания (факельное, слоевое), а также эффективности работы природоохранного оборудования и специальных экозащитных мер проводится прогнозная оценка выбросов в атмосферу загрязняющих веществ.

Расчет эмиссии вредных веществ в элементы природной среды выполняется с использованием существующих методик определения выбросов от объектов энергетики [Сборник методик ..., 1986; Методика определения ... , 1999; Методики определения ..., 1984], а также указаний по количественному определению выбросов парниковых газов [Mетодические указания ...] и рекомендаций по оценке количества золошлаковых отходов [Методические рекомендации по разработке ..., 1998].

Прогноз суммарных выбросов в атмосферу области представлен для трех категорий хозяйствующих объектов: крупные энергообъекты (ТЭС), котельные и непосредственное потребление (неэнергетический сектор). К энергетике отнесены ТЭС и котельные.

В расчетах принято, что степень улавливания твердых частиц на энергетических объектах, использующих в качестве топлива уголь, для ТЭС в среднем по области составляет $95 \%$ (2015 г.) с увеличением до 97 \% к 2035 году. 
Для крупных котельных предусмотрено увеличение степени пылеулавливания в среднем по области с $70 \%$ (2015 г.) до $80 \%$ к 2035 году. В перспективе для котельных малой мощности предусматривается применение мер по подготовке топлива к сжиганию, что позволит снизить выброс твердых частиц на 20-30 \% к 2035 году. Внедрение в крупных котельных рециркуляции дымовых газов и ступенчатого сжигания топлива позволит снизить и выбросы оксидов азота до 30 \% к 2035 году.

Для снижения выбросов оксидов серы, которые в настоящее время доминируют в эмиссии всех ТЭС Иркутской области, наиболее эффективными являются методы химического взаимодействия между загрязняющим веществом и реагентом: абсорбция, адсорбция, каталитическое окисление [Сжигание топлива ..., 2017]. Для проведения прогнозных оценок в исследовании по ТЭК Иркутской области принято снижение выбросов $\mathrm{SO}_{2}$ за счет использования на крупных ТЭС мокрых систем золоулавливания (с трубами Вентури). Соответственно, выброс оксидов серы снижается на $20 \%$ как в 2015 г., так и в перспективе.

Согласно расчетам, суммарные выбросы в атмосферу в период с 2015 по 2035 г. снизятся в 1,2 раза и к 2035 г. составят 488 тыс. т, при этом выбросы от ТЭС снизятся в 1,5 раза (с 277 до 185 тыс. т), от котельных - на 24 \% (с 204 до 164 тыс. т).

С 2025 г. развитие энергетики предполагает значительные изменения, когда наряду с природоохранными мероприятиями свою роль сыграет и рост доли природного газа в топливном балансе энергогенерирующих предприятий.

Структура вклада различных хозяйствующих объектов в суммарный выброс к 2035 г. характеризуется снижением доли ТЭС с $45 \%$ в 2015 г. до $38 \%$, доля котельных в суммарном выбросе не изменится, а в неэнергетическом секторе возрастет с 21 до $29 \%$. Рост выброса в секторе непосредственного потребления обусловлен увеличением сжигания здесь угля и нефтепродуктов.

Ингредиентный состав выбросов в среднем по области характеризуется преобладанием твердых частиц, доля которых в 2015 г. составила $47 \%$, а к 2035 г. снизится до $44 \%$. Основными источниками эмиссии на перспективу до 2035 г. в Иркутской области останут- ся крупные ТЭС. В ингредиентной структуре выбросов ТЭС преимущественной примесью останутся оксиды серы, доля которых в 2015 г. равнялась $60 \%$, а к 2035 г. увеличится до $64 \%$ при их количественном снижении в 1,4 раза. В структуре выбросов ТЭС доля оксидов азота составит 14-16 \% как в настоящее время, так и в перспективе. Существенная доля в выбросах котельных как в 2015 г., так и в перспективе до 2035 г. будет представлена выбросами твердых частиц - около 80 \% (см. рис. 1).

Другим важным аспектом эмиссии загрязняющих веществ в атмосферу при сжигании органического топлива является выброс парниковых газов (диоксида углерода). В настоящее время оценка количества парниковых газов носит рекомендательный характер. Однако предприятия должны документировать количественные объемы парниковых газов и включать эту информацию в пояснительную записку к годовым отчетам о своей деятельности.

В соответствии с «Методическими указаниями» [Методические указания ...] для хозяйствующих объектов Иркутской области, сжигающих органическое топливо, проведены расчеты суммарных выбросов диоксида углерода, которые в исходном 2015 г. оценивались в 32,5 млн тонн. С учетом перспектив топливоснабжения выброс $\mathrm{CO}_{2}$ может увеличиться на 6,2 млн т к 2035 г. - до 38,7 млн тонн.

Основными источниками эмиссии парниковых газов являются крупные угольные ТЭС, однако к 2035 г. сопоставимый с ТЭС объем выброса диоксида углерода будут поставлять предприятия неэнергетического сектора, который за период 2015-2035 гг. увеличится на $45 \%$.

Зависимость количества выбросов $\mathrm{CO}_{2}$ от вида сжигаемого топлива различными стационарными объектами показывает, что снижение потребления угля способствует снижению выбросов парниковых газов (см. рис. 2).

Рост сжигания нефтетоплива, особенно в секторе непосредственного потребления, связан с увеличением выброса диоксида углерода, и к 2035 г. он составит 7,7 млн т примерно столько же выбрасывается при сжигании природного газа за счет увеличения его доли в структуре топливопотребления. 


\section{РЕГИОНАЛЬНАЯ ЭКОНОМИКА}

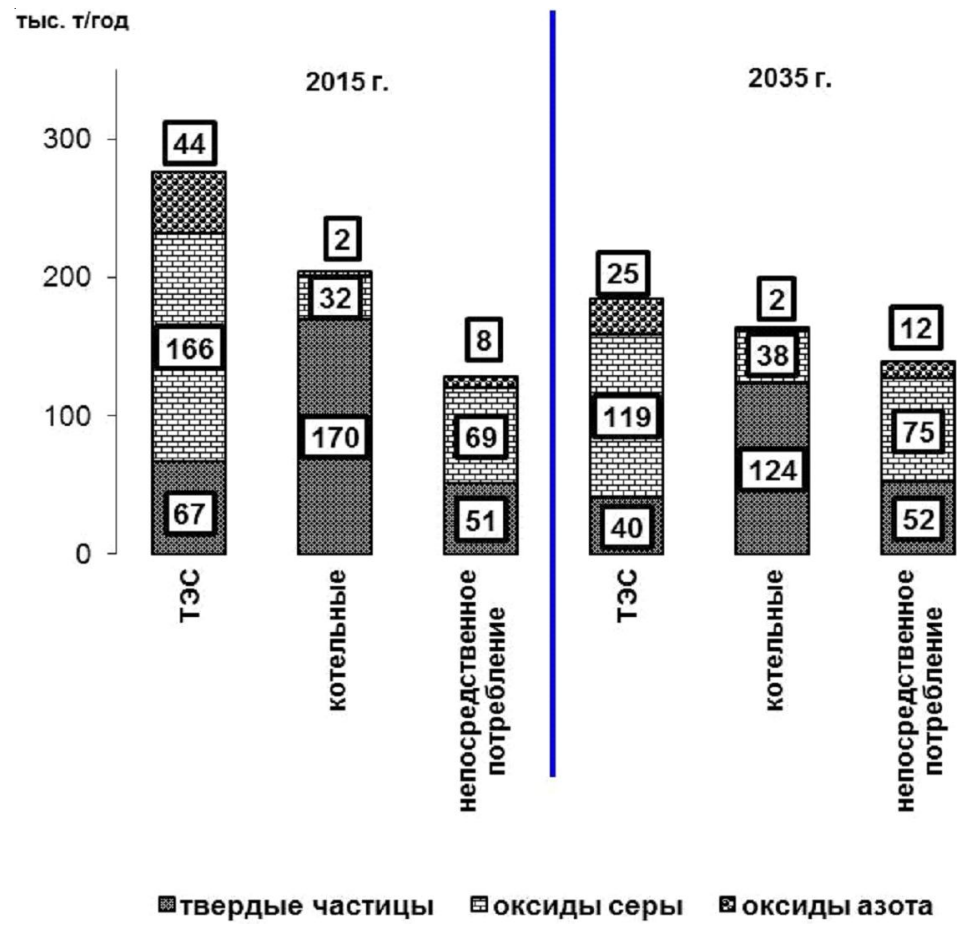

Рис. 1. Структура выбросов загрязняющих веществ в Иркутской области

Примечание. Составлено авторами.

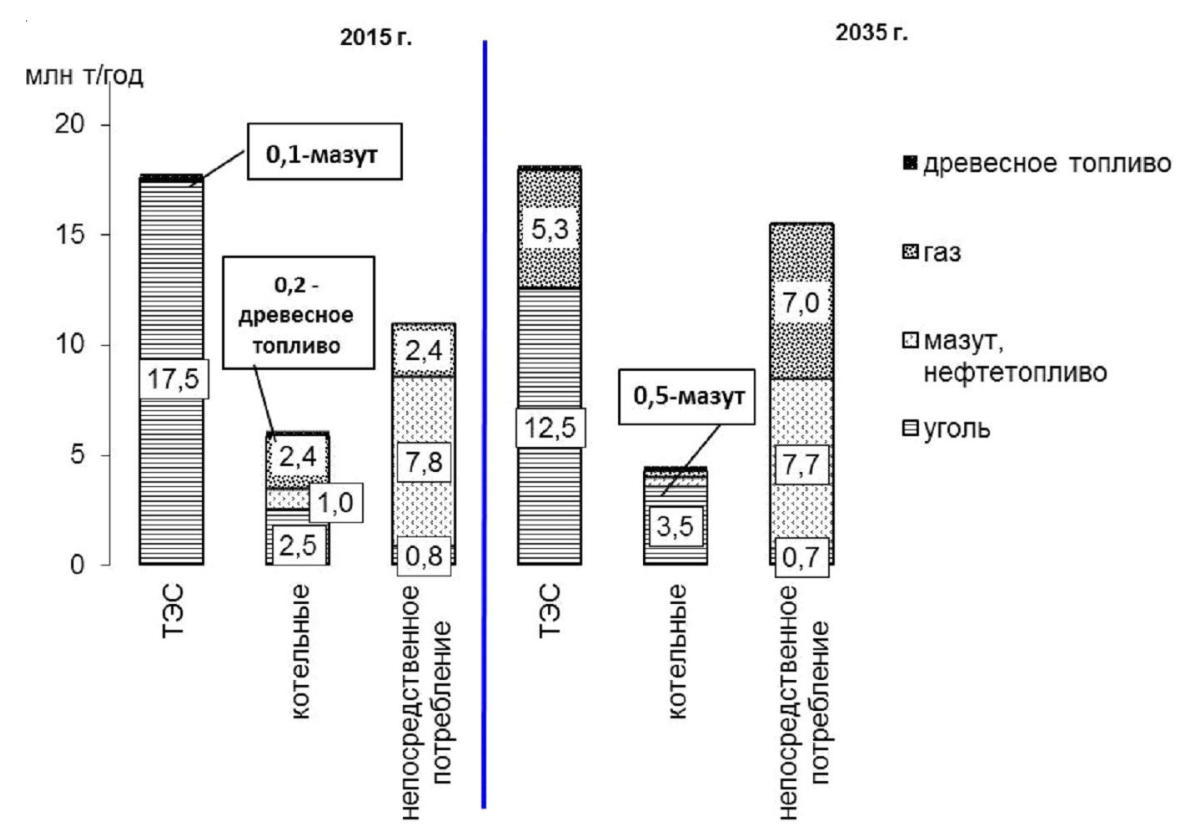

Рис. 2. Структура объектов по видам топлива в выбросе $\mathrm{CO}_{2}$ в Иркутской области

Примечание. Составлено авторами.

В целом вклад энергетики в суммарный выброс $\mathrm{CO}_{2}$ в области оценивается в 21,5 млн т в 2015 г. и в 22,6 млн т в 2035 г., преимущественно за счет ТЭС.

Другим экологическим показателем развития энергетики области является образова- ние золошлаковых отходов, количество которых, по укрупненным оценкам, зависит от объема сжигаемого угля. С учетом перспективных балансов топливопотребления к концу рассматриваемого периода его количество снизится в 1,5 раза. В 2035 г. объем золошла- 
ков от объектов энергетики оценивается в 1,51,8 млн тонн. В связи со значительным количеством отходов, уже накопленных на территории области, следует предусмотреть решение вопроса их утилизации.

Таким образом, перспективное развитие энергетики области с учетом реализации инноваций позволит снизить антропогенную нагрузку на природную среду в части выбросов в атмосферу в сравнении с 2015 г. на 122 тыс. тонн. Доля энергетики в суммарном воздействии снизится с $79 \%$ до $71 \%$ (табл. 4).

Расчеты показали, что наименьшее количество удельных выбросов к 2035 г. в неэнергетическом секторе экономики составит 16 кг/т у.т. Удельный выброс на крупных ТЭС оценивается в 21 кг/т у.т. Наибольший показатель удельных выбросов - у котельных, с максимальным значением в период до 2020 г. из-за отсутствия природоохранных мер в этот период (табл. 5).

Суммарный удельный выброс от ТЭС и котельных в области снизится с 40 кг/т у.т. в 2015 г. до 32 кг/т у.т. к 2035 году.

Таким образом, инновационное развитие энергетики, включающее широкое вовлечение природного газа в топливный баланс, использование наилучших доступных технологий позволят существенно снизить антропогенную нагрузку на природную среду, и в большей степени - на атмосферу.

\section{Заключение}

В статье показаны основные направления инновационного развития энергетики Иркутской области и дана экологическая оценка этого процесса.

В ходе исследований получены следующие результаты: разработана информационноаналитическая база инновационных технологий для комплексного анализа и долгосрочного прогнозирования инновационного развития энергетики; выполнен обзор зарубежных и российских источников по применению инновационных технологий в энергетике; разработана информационная база инновационных природоохранных мер в энергетике; дана оценка влиянию инновационного развития ТЭК на экологическое состояние области.

Внедрение инновационных технологий оказывает значительное влияние на рост энергоэффективности экономики области, повышение конкурентоспособности региона, снижение экологических проблем. Инновационное развитие энергетики окажет положительный эффект на экологическое состояние окружающей среды, что улучшит качество жизни населения Иркутской области.

Полученные результаты будут использоваться в исследованиях по прогнозированию инновационного развития ТЭК Иркутской области и выработке рекомендаций по использованию эффективных инновационных

Вклад ТЭС и котельных Иркутской области

Таблица 4 в суммарный расчетный выброс до 2035 г.

\begin{tabular}{|l|c|c|c|c|}
\hline \multicolumn{1}{|c|}{ Показатель } & 2015 г. & 2020 г. & 2025 г. & 2035 г. \\
\hline Выброс, всего & 610 & 584 & 602 & 488 \\
\hline Выброс от энергетики, тыс. т/год & 481 & 445 & 466 & 349 \\
\hline Вклад энергетики, \% & 79 & 76 & 77 & 71 \\
\hline
\end{tabular}

Примечание. Рассчитано авторами.

Удельные выбросы в атмосферу Иркутской области, кг/т у.т.

\begin{tabular}{|c|l|c|c|c|c|}
\hline Сценарий & \multicolumn{1}{|c|}{ Объекты } & 2015 г. & 2020 г. & 2030 г. & 2035 г. \\
\hline \multirow{3}{*}{$\begin{array}{l}\text { Стратегический } \\
\text { (инновационный) }\end{array}$} & ТЭС & 40 & 37 & 25 & 21 \\
\cline { 2 - 6 } & Котельные & 97 & 97 & 83 & 79 \\
\cline { 2 - 6 } & Неэнергетический сектор & 24 & 25 & 19 & 16 \\
\cline { 2 - 6 } & В целом по области, \% & 46 & 40 & 29 & 25 \\
\hline
\end{tabular}

Примечание. Рассчитано авторами. 
технологий в схемах энергоснабжения потребителей.

Научные разработки могут быть использованы региональными органами власти и энергетическими компаниями по внедрению инновационных технологий в энергетике с целью надежного и экологически эффективного энергоснабжения потребителей Иркутской области.

\section{ПРИМЕЧАНИЯ}

${ }^{1}$ Исследование выполнено при финансовой поддержке РФФИ и Правительства Иркутской области, проект № 17-48-380002 p_а «Обоснование приоритетных направлений экологически чистого энерго-, топливоснабжения потребителей Иркутской области: методические подходы и их практическая реализация».

The reported study was funded by RFBR and the Irkutsk region government, project no. 17-48380002 p_a "Substantiation of priority directions of ecologically clean energy and fuel supply to consumers in the Irkutsk region: methodical approaches and their practical implementation".

${ }^{2}$ Международное энергетическое агентство (МЭА; англ. International Energy Agency, IEA) - автономный международный орган в рамках Организации экономического сотрудничества и развития (ОЭСР). Насчитывает 29 стран-участниц.

${ }^{3}$ По данным Росстата, объем потребления природного топлива в России за 2017 г. составил 1087,7 млн т у.т.

\section{СПИСОК ЛИТЕРАТУРЫ}

Баланс энергоресурсов за 2018 г. // Федеральная служба государственной статистики РФ. Электрон. текстовые дан. - Режим доступа: http://www.gks.ru/free_doc/new_site/business/ prom/en_balans.htm (дата обращения: 15.06.2019). - Загл. с экрана.

Внедрение инновационных технологий и современных материалов в отраслях топливно-энергетического комплекса за период до 2018 г. План мероприятий («дорожная карта»). - 2014 // Минэнерго РФ. - Электрон. текстовые дан. Режим доступа: https://minenergo.gov.ru/ node/8915 (дата обращения: 15.06.2019). - Загл. с экрана.

Методика определения выбросов загрязняющих веществ в атмосферу при сжигании топлива в котлах производительностью менее 30 тонн пара в час или менее 20 Гкал в час. - М. : Госкомитет РФ по охране окружающей среды, 1999. - 53 с.

Методики определения валовых выбросов загрязняющих веществ в атмосферу от котлов тепловых электростанций. - М. : СПО Союзтехэнерго, 1984. - $18 \mathrm{c}$.

Методические рекомендации по определению технологии в качестве наилучшей доступной : утв. приказом М-ва промышленности и торговли РФ от 31.03.2015 № 665 // Электронный фонд правовой и нормативно-технической информации. - Электрон. текстовые дан. Режим доступа: http://docs.cntd.ru/document/ 420295635 (дата обращения: 15.06.2019). - Загл. с экрана.

Методические рекомендации по разработке проекта нормативов предельного размещения отходов для теплоэлектростанций, теплоэлектроцентралей, промышленных и отопительных котельных / А. И. Трегубов [и др.]. - СПб. : [б. и.], 1998 // Электронный фонд правовой и нормативно-технической информации. Электрон. текстовые дан. - Режим доступа: http://docs.cntd.ru/document/1200043975 (дата обращения: 15.06.2019). - Загл. с экрана.

Методические указания и руководство по количественному определению объемов выбросов парниковых газов организациями, осуществляющими хозяйственную и иную деятельность в Российской Федерации : утв. приказом Минприроды России от 30.06.2015 г. // Электронный фонд правовой и нормативно-технической информации. - Электрон. текстовые дан. - Режим доступа: http:// docs.cntd.ru/document/420287801 (дата обращения: 15.06.2019). - Загл. с экрана.

Национальный проект «Интеллектуальная энергетическая система России». - 2016 // Минэнерго РФ. - Электрон. текстовые дан. - Режим доступа: https://minenergo.gov.ru/node/ 8917 (дата обращения: 15.06.2019). - Загл. с экрана.

Очистка выбросов вредных (загрязняющих) веществ в атмосферный воздух при производстве продукции (товаров), а также при проведении работ и оказании услуг на крупных предприятиях : информ.-техн. справ. по наилучшим доступным технологиям (ИТС 22-2016). - М. : [б. и.], 2016. - 212 с.

Прогноз научно-технологического развития отраслей ТЭК России на период до 2035 года. - 2016 // Минэнерго РФ. - Электрон. текстовые дан. Режим доступа: https://minenergo.gov.ru/node/ 8914 (дата обращения: 15.06.2019). - Загл. с экрана. 
Распоряжение Правительства Российской Федерации от 19.03.2014 № 398-р «Об утверждении комплекса мер, направленных на отказ от использования устаревших и неэффективных технологий, переход на принципы наилучших доступных технологий и внедрение современных технологий» // Электронный фонд правовой и нормативно-технической информации. - Электрон. текстовые дан. - Режим доступа: http://docs.cntd.ru/document/499084212 (дата обращения: 15.06.2019). - Загл. с экрана.

Сборник методик по расчету выбросов в атмосферу загрязняющих веществ различными производствами. - Л. : Госкомгидромет, 1986. C. 1-27.

Сжигание топлива на крупных установках в целях производства энергии : информ.-техн. справ. по наилучшим доступным технологиям (ИТС 38-2017). М. : [б. и.], 2017. - 280 с.

Энерджинет: «дорожная карта». - 2016 // Минэнерго РФ. - Электрон. текстовые дан. - Режим доступа: https://minenergo.gov.ru/node/8916 (дата обращения: 15.06.2019). - Загл. с экрана.

Японские энергоэффективные технологии. - 2017 // Японский бизнес-альянс по продвижению интеллектуальных энергетических систем во всем мире. - Электрон. текстовые дан. - Режим доступа: https:/www.jase-w.eccj.or.jp/technologies-r/ pdf/Japanese_Energy_Efficient_Technologies.pdf (дата обращения: 15.06.2019). - Загл. с экрана.

Energy Technology Perspectives 2017 // Сайт Международного энергетического агентства. Электрон. текстовые дан. - Режим доступа: http:/www.iea.org/etp2017/summary/ (дата обращения: 15.06.2019). - Загл. с экрана.

Japanese Smart Energy Products \& Technologies. 2017 // Японский бизнес-альянс по продвижению интеллектуальных энергетических систем во всем мире. - Электрон. текстовые дан. - Режим доступа: https://www.jasew.eccj.or.jp/technologies-r/ (дата обращения: 15.06.2019). - Загл. с экрана.

\section{REFERENCES}

Balans energoresursov za 2018 g. Federalnaya sluzhba gosudarstvennoy statistiki RF [Energy Balance for 2017. Federal State Statistics Service of the Russian Federation]. URL: http:// www.gks.ru/free_doc/new_site/business/prom/ en_balans.htm (accessed 15 June 2019).

Vnedrenie innovatsionnykh tekhnologiy i sovremennykh materialov $\mathrm{v}$ otraslyakh toplivno-energeticheskogo kompleksa za period do 2018 g. Plan meropriyatiy («dorozhnaya karta») [Introduction of Innovative Technologies and Modern Materials in the Fuel and Energy Sector for the period up to 2018. The Action Plan ("Road Map")]. Minenergo RF [Ministry of Energy of the Russian Federation]. URL: https://minenergo.gov.ru/node/8915 (accessed 15 June 2019).

Metodiki opredeleniya valovykh vybrosov zagryaznyayushchikh veshchestv $v$ atmosferu ot kotlov teplovykh elektrostantsiy [Methods for Determining Gross Emissions of Pollutants into the Atmosphere from Boilers of Thermal Power Plants]. Moscow, SPO Soyuztekhenergo, 1984. $18 \mathrm{p}$.

Metodicheskie rekomendatsii po opredeleniyu tekhnologii $v$ kachestve nailuchshey dostupnoy, utverzhdennye prikazom Ministerstva promyshlennosti i torgovli RF ot 31.03.2015 za № 665 [Guidelines for Determining the Technology as the Best Available, Approved by the Order of the Ministry of Industry and Trade of the Russian Federation of March 3, 2015 no. 665]. Elektronnyy fond pravovoy $i$ normativno-tekhnicheskoy informatsii [Electronic Fund of Legal and Regulatory Technical Information]. URL: http:// docs.cntd.ru/document/420295635 (accessed 15 June 2019).

Metodicheskie rekomendatsii po razrabotke proekta normativov predelnogo razmeshcheniya otkhodov dlya teploelektrostantsiy, teploelektrotsentraley, promyshlennykh i otopitelnykh kotelnykh, 1998 [Methodological Recommendations on the Development of Draft Standards for the Maximum Waste Disposal for Thermal Power Plants, Combined Heat and Power Plants, Industrial and Heating Boiler Houses, 1998]. Elektronnyy fond pravovoy i normativnotekhnicheskoy informatsii [Electronic Fund of Legal and Regulatory Technical Information]. URL: http://docs.cntd.ru/document/1200043975 (accessed 15 June 2019).

Natsionalnyy proekt «Intellektualnaya energeticheskaya sistema Rossii», 2016 [National Project "Intelligent Energy System of Russia”, 2016]. Minenergo RF [Ministry of Energy of the Russian Federation]. URL: https://minenergo.gov.ru/node/8917 (accessed 15 June 2019).

Ochistka vybrosov vrednykh (zagryaznyayushchikh) veshchestv $v$ atmosfernyy vozdukh pri proizvodstve produktsii (tovarov), a takzhe pri provedenii rabot $i$ okazanii uslug na krupnykh predpriyatiyakh: inform.-tekhn. sprav. po nailuchshim dostupnym tekhnologiyam (ITS 22-2016) [Purification of Emissions of Harmful (Polluting) Substances into the Air During 


\section{РЕГИОНАЛЬНАЯ ЭКОНОМИКА}

Manufacturing Products (Goods), as well as During Conducting Work and the Providing Services at Large Enterprises. Information and Technical Reference on the Best Available Technologies (ITS 22-2016)]. Moscow, 2016.212p.

Prognoz nauchno-tekhnologicheskogo razvitiya otrasley TEK Rossii na period do 2035 goda [Forecast of the Scientific and Technological Development of the Fuel and Energy Complex of Russia for the Period Until 2035]. Minenergo $R F$ [Ministry of Energy of the Russian Federation]. URL: https://minenergo.gov.ru/ node/8914 (accessed 15 June 2019).

Rasporyazhenie Pravitelstva Rossiyskoy Federatsii ot 19.03.2014 № 398-r «Ob utverzhdenii kompleksa mer, napravlennykh na otkaz ot ispolzovaniya ustarevshikh i neeffektivnykh tekhnologiy, perekhod na printsipy nailuchshikh dostupnykh tekhnologiy i vnedrenie sovremennykh tekhnologiy»" [Decree of the Government of the Russian Federation of March 19, 2014 no. 398-p "On Approving a Complex of Measures Aimed at Abandoning the Use of Obsolete and Inefficient Technologies, the Transition to the Principles of the Best Available Technologies and the Introduction of Modern Technologies»]. Elektronnyy fond pravovoy i normativnotekhnicheskoy informatsii [Electronic Fund of Legal and Regulatory-Technical Information]. URL: http://docs.cntd.ru/document/499084212 (accessed 15 June 2019).

Sbornik metodik po raschetu vybrosov $v$ atmosferu zagryaznyayushchikh veshchestv razlichnymi proizvodstvami [Collection of Methods for Calculating Emissions into the Atmosphere of
Pollutants by Various Industries]. Leningrad, Goskomgidromet, 1986, pp. 1-27.

Szhiganie topliva na krupnykh ustanovkakh $v$ tselyakh proizvodstva energii: inform.-tekhn. sprav. po nailuchshim dostupnym tekhnologiyam (ITS 382017) [Burning Fuel in Large Plants for Energy Production. Information and Technical Reference on the Best Available Technologies (ITS 38-2017)]. Moscow, 2017.280 p.

Enerdzhinet «dorozhnaya karta», 2016 [Energynet "Road Map", 2016]. Minenergo RF [Ministry of Energy of the Russian Federation]. URL: https:/ /minenergo.gov.ru/node/8916 (accessed 15 June 2019).

Yaponskie energoeffektivnye tekhnologii, 2017 [Japanese Energy-Efficient Technologies, 2017]. Yaponskiy biznes-alyans po prodvizheniyu intellektualnykh energeticheskikh sistem vo vsem mire [Japanese Business Alliance for the Promotion of Intelligent Energy Systems Worldwide]. URL: https:// www.jase-w.eccj.or.jp/technologies-r/pdf/ Japanese_Energy_Efficient_Technologies.pdf. (accessed 15 June 2019).

Energy Technology Perspectives. 2017. Sayt Mezhdunarodnogo energeticheskogo agentstva [Website of the International Energy Agency]. URL: http://www.iea.org/etp2017/ summary/ (accessed 15 June 2019).

Japanese Smart Energy Products \& Technologies 2017. Yaponskiy biznes-alyans po prodvizheniyu intellektualnykh energeticheskikh sistem vo vsem mire [Japanese Business Alliance for the Promotion of Intelligent Energy Systems Worldwide]. URL: https://www.jase-w.eccj.or.jp/ technologies-r/ (accessed 15 June 2019). 


\section{Information About the Authors}

Boris G. Saneev, Doctor of Sciences (Engineering), Professor, Head of the Department of Regional Energy Problems, Melentiev Energy Systems Institute of the Siberian Branch of the Russian Academy of Sciences, Lermontova St., 130, 664033 Irkutsk, Russian Federation, saneev@isem.irk.ru, https:// orcid.org/0000-0002-0571-6986

Elena P. Majsjuk, Candidate of Sciences (Economy), Senior Researcher, Laboratory of Energy Supply for Distributed Consumers, Melentiev Energy Systems Institute of the Siberian Branch of the Russian Academy of Sciences, Lermontova St., 130, 664033 Irkutsk, Russian Federation, maysyuk@isem.irk.ru, https://orcid.org/0000-0002-5127-1607

Svetlana Ju. Muzychuk, Candidate of Sciences (Economy), Leading Researcher, Laboratory of the Fuel and Energy Complex of Siberia and the Far East, Melentiev Energy Systems Institute of the Siberian Branch of the Russian Academy of Sciences, Lermontova St., 130, 664033 Irkutsk, Russian Federation,muz@isem.irk.ru, https://orcid.org/0000-0002-7378-178X

\section{Информация об авторах}

Борис Григорьевич Санеев, доктор технических наук, профессор, заведующий отделом региональных проблем энергетики, Институт систем энергетики им. Л.А. Мелентьева Сибирского отделения РАН, ул. Лермонтова, 130, 664033 г. Иркутск, Российская Федерация, saneev@isem.irk.ru, https://orcid.org/0000-0002-0571-6986

Елена Петровна Майсюк, кандидат экономических наук, старший научный сотрудник лаборатории энергоснабжения децентрализованных потребителей, Институт систем энергетики им. Л.А. Мелентьева Сибирского отделения РАН, ул. Лермонтова, 130, 664033 г. Иркутск, Российская Федерация, maysyuk@isem.irk.ru, https://orcid.org/0000-0002-5127-1607

Светлана Юрьевна Музычук, кандидат экономических наук, ведущий научный сотрудник лаборатории ТЭК Сибири и Дальнего Востока, Институт систем энергетики им. Л.А. Мелентьева Сибирского отделения РАН, ул. Лермонтова, 130, 664033 г. Иркутск, Российская Федерация, muz@isem.irk.ru, https://orcid.org/0000-0002-7378-178X 